\title{
Characterization of Spent Prebaked Aluminium Carbon Anode as a Source of Fuel for Foundrymen
}

\author{
A. Andrews*, E. Gikunoo, B. K. Kyei-Fram, R. Sarfo \\ Department of Materials Engineering, Kwame Nkrumah University of Science and Technology, \\ Kumasi, Ghana \\ *Corresponding Author Tel.: +233-54-1019379; Fax: +233-3220-60238 \\ Email Address: anthonydrews@gmail.com
}

\begin{abstract}
Small scale foundries in Ghana are in search of a suitable coke for their foundry operations since there is no coal mine in Ghana. Two grades of spent prebaked aluminium carbon anodes (herein referred to as grade $P$ and grade $K$ ), which are remnants from the aluminium electrolysis at Volta Aluminum Company (VALCO), an aluminium smelting company in Ghana, have been characterized to assess their quality and use as foundry coke. Proximate analysis and X-ray diffraction techniques have been used for their quality assessments. Coke grade $P$ had lower moisture content, volatile matter and ash content compared to grade $K$. In both grades, sulphur and phosphorus contents were within requirements of a quality foundry coke. However, the volatile matter and ash contents of both grades were not satisfactory. Fixed carbon contents in both grades were below that of a quality foundry coke. Carbon structure of coke found in both grades is crystalline in nature. The crystalline width, Lc, was calculated to be $4.05 \AA$ and $5.12 \AA$ for grade $K$ and $P$, respectively.
\end{abstract}

Keywords: Foundry coke, proximate analysis, x-ray diffraction, crystallite size

\section{INTRODUCTION}

In foundry technology, very high temperatures are required to melt metal scraps. Modern foundry practices use electric and induction furnaces for melting. However, local small scale foundries (SSFs) in Ghana cannot afford electric furnaces due to the expensive nature as well as high electricity tariffs. They have rather resorted to the use of cupola furnaces manufactured 
locally for melting. The cupolas use foundry coke as source of fuel. There are different types of coke which includes metallurgical coke, foundry coke, formed coke, coke for electric furnaces and coke for resistor in graphitization furnaces [1-6]. All coke is made from coal but not all coals can be used to make coke. Blast furnace coke (metallurgical coke) can be made from a greater variety of metallurgical coals than foundry coke. Foundry coke must be made from low volatility, low sulfur coals. These coal types are in very short supply. The use of coke is preferred to coal because coke does not give a lot of pollution products as compared to coal and produces high temperatures when burnt because of the high carbon content. Foundry coke has few impurities and high carbon content. The quality of foundry coke has direct impact on the quality of melt, control product consistency, increase productivity and minimizes waste generation at foundry sites [2].

There is no coal mine in Ghana. Volta Aluminium Company (VALCO) import petroleum coke from overseas for their aluminium smelting operations. Petroleum coke is used to produce prebaked aluminium carbon anodes which are then used for the smelting of aluminium. Remnants of the spent prebaked aluminium carbon anodes (SPACAs) are landfilled. Until recently, there was no use for the SPACAs. SSFs are now using this material as a source of fuel for their foundry operations. Apart from being the only source of coke, it is also less expensive compared to importing foundry coke from overseas or using electricity. The SPACAs come in two major grades and are sold by local coke dealers. Properties of these spent carbon anodes are not known but foundrymen believe that they do not meet the requirement of a good foundry coke. Apart from the difficulties in getting quality foundry coke, the quality of scrap streams is also in doubt. When high levels of ash from poor quality coke, coupled with the slag-promoting characteristics of sub-standard scrap, are charged into a cupola furnace, reduced cupola melting efficiency, reduced metal quality and slag buildup in downstream metal holding vessels becomes a concern.

A number of tests have been developed for the quantitative assessment of the properties of coke which influence the operation of cupolas [7]. One of the most common tests is the use of proximate analysis [5]. Coke reactivity is also influenced by carbon structure and can be measured by X-ray diffraction technique [8]. High temperatures lead to coke graphitization (i.e. increased order of carbon structure) [9]. Since spent carbon anodes have been subjected to high temperatures during smelting operations, it is expected that the carbon structure will change thereby affecting subsequent coke reactivity. Graphite structure can be described by a regular, vertical stacking of hexagonal aromatic layers with the degree of ordering characterized by the vertical dimension of the crystallite (Lc) [10]. This paper therefore presents the results on the proximate analysis and carbon structure of the SPACAs studied. The results are used to assess the quality of the anodes as a source of fuel and its impact on foundry operations.

\section{MATERIALS AND METHODS}




\subsection{Materials}

Samples were collected for analysis based on ASTM standard D 346 (2004). Two grades of SPACA samples (herein referred to as grade $\mathrm{P}$ and grade $\mathrm{K}$ ) were taken from foundry site at Suame-Magazine, a suburb in Kumasi in the Ashanti region of Ghana. Samples were taken at the point of discharge of the SPACAs. $500 \mathrm{~kg}$ of each grade were sampled for analysis. Samples were taken in the lumped state $(6-8 \mathrm{~cm})$. Each grade was crushed with a jaw crusher, milled and screened with a $250 \mu \mathrm{m}$ size. Representative samples of the undersize fraction were used for all analyses. The two grades were observed to be of different shapes and sizes. Grade $\mathrm{K}$ had coarser particles and harder compared to grade $\mathrm{P}$ which was of finer particles and relatively softer. Densities of the samples investigated were determined using Achemides principle method before carrying out proximate analysis.

\subsection{Methods}

\subsubsection{Determination of the moisture content}

Moisture content was determined according to ASTM standard D 3173 (2003). Two porcelain capsules were cleaned, labelled, and dried in an oven at $110^{\circ} \mathrm{C}$ for 15 minutes. Capsules were allowed to cool in a desiccator over a desiccant before weighing using electronic balance. $1 \mathrm{~g}$ of grade $\mathrm{K}$ and grade $\mathrm{P}$ samples were weighed into the capsules, respectively. Their contents were weighed and dried at $110^{\circ} \mathrm{C}$ in the oven for 1 hour. The capsules and their contents were then covered, removed, and cooled in a desiccator for 30 minutes and re-weighed. The loss in weight in each grade sample accounted for the moisture content.

\subsubsection{Determination of ash content}

Ash content was determined according to ASTM standard D 3174 (2004). Two silica crucibles were cleaned, labelled, preheated in the muffle furnace at $500^{\circ} \mathrm{C}$ for 1 hour. They were cooled in a desiccator and weighed. $1 \mathrm{~g}$ of grade $\mathrm{K}$ and grade $\mathrm{P}$ samples were measured onto each crucible and heated in the muffle furnace to $500^{\circ} \mathrm{C}$ within 1 hour. The temperature was further increased to $950^{\circ} \mathrm{C}$ within another 1 hour and the temperature maintained at that temperature for another 2 hours. The crucibles were removed from the furnace, covered and cooled in desiccators before weighing. The weight of the incombustible coke in each grade sample accounted for the ash content.

\subsubsection{Determination of the volatile matter}

The volatile matter was determined based to ASTM standard D 3175 (2002). Two silica crucibles were cleaned, labelled, and preheated in the muffle furnace at $900^{\circ} \mathrm{C}$ for 3 minutes with 
their lids on. $1 \mathrm{~g}$ of grade $\mathrm{K}$ and grade $\mathrm{P}$ samples were weighed into the crucibles and heated in the muffle furnace at $900^{\circ} \mathrm{C}$ for 7 minutes. They were removed from the furnace, cooled in desiccators and reweighed. The loss in weight minus the amount of moisture equals the volatile matter.

\subsubsection{Determination of the amount of fixed carbon}

This was done by calculation (ASTM D 3172, 2002). The percentage moisture (M), ash (A), and volatile matter $(\mathrm{V})$, were subtracted from 100 . That is,

Fixed carbon $=100-\mathrm{M}-\mathrm{A}-\mathrm{V}$

\subsubsection{Determination of total sulphur}

Total sulphur content was determined based on ASTM standard D 4239 (2005). 1g of grade K and grade $\mathrm{P}$ samples were weighed into two 30ml porcelain crucibles, respectively, labelled and mixed with $3 g$ of Eschka mixture (two parts of magnesium oxide with 1 part anhydrous sodium carbonate). A blank sample (without coke) was prepared in a similar manner. The crucibles were placed in a cold muffle furnace and gradually heated to $800^{\circ} \mathrm{C}$ for about 1 hour. The temperature was maintained for 1 hour. The crucibles were removed, slightly cooled and stirred to ensure that no black coke particles occur. The crucibles were them emptied into 400ml beakers containing $100 \mathrm{mls}$ of hot water. Digestion was done for 45 minutes, with occasional stirring. The solution in each beaker was now decanted through a 540 filter paper into a $400 \mathrm{ml}$ beaker. The insoluble materials in the beakers were thoroughly washed with hot water, filtered and washed again. The process was repeated 5 times. The filtrate volume obtained was $250 \mathrm{ml}$. The residues were then discarded. Three drops of methyl orange indicator was added. Sodium hydroxide was also added dropwise until the solution was turned neutral. $1 \mathrm{ml}$ of hydrochloric acid was then added followed with $25 \mathrm{ml}$ of potassium sulphate using an 'A' grade pipette. The samples were then heated to boil. 10mls of barium chloride solution was slowly added to each solution while stirring. The solutions were maintained near boiling for 30 minutes and then left to stand overnight. The solutions were filtered with different No 42 paper and thoroughly washed with hot water. The wet filter papers were placed in a crucible and ignited for 15 minutes. The papers were gradually smoked off in the muffle furnace, avoiding burning. The temperature was then gradually raised to $800^{\circ} \mathrm{C}$ and maintained for 1 hour. The crucibles were cooled and barium sulphate weighed. The total sulphur in each sample was calculated as follows:

Total sulphur $(\mathrm{wt} \%)=[13.74 \times(X-Y+0.008)] / Z$

where $X$ is mass of barium sulphate from sample, $Y$ is mass of barium sulphate from blank, and $Z$ is mass of sample used. 


\subsubsection{Chemical analysis}

X-ray fluorescence (XRF-Spectro X-LAB 2000) was used to determine the chemical composition of the spent prebaked aluminium carbon anode types investigated.

\subsubsection{XRD analysis}

Carbon structure of coke is often related to the reactivity as well as graphitization and can be measured by the X-ray diffraction. Siemens D5000 X-ray diffractometer was used to record scattering intensities of samples by using monochromatic Copper Ka radiation (40 kV, $40 \mathrm{~mA}$ ) as the X-ray source. Samples were packed into an aluminium holder and scanned over an angular range from $5-80^{\circ}$ by using a step size of $0.02^{\circ}$ and collecting the scattering intensity for 1 second at each step. The XRD data was processed to obtain monocrystallite height (Lc) in SPACA materials. The average stacking height of (002) carbon peak was calculated using Scherrer's equation as follows:

$$
L_{c}=(K \lambda) / B \cos \theta
$$

where $K$ is the Scherrer's constant $(K=0.89), \lambda$ is the X-ray wavelength $(\lambda=0.5406 \AA), \theta$ is the Bragg angle, and $B$ is the half-height width (FWHM) of the (002) diffraction.

\subsection{Results}

The results of the proximate analyses are summarised in Table 1. For comparison, proximate analyses of Indian coke, Chinese coke, Nigerian coke and Nigerian coals have also been provided.

The specific gravities of grade $\mathrm{K}$ and grade $\mathrm{P}$ were determined to be 2.06 and 1.74 , respectively. The specific gravities recorded in this work were very low. Both grades have very low porosity. The average moisture contents of grade $\mathrm{K}$ and grade $\mathrm{P}$ were determined to be $0.63 \%$ and $0.01 \%$, respectively. The moisture contents recorded were within the range published for the Chinese foundry coke $(\leq 5)$ and comparable to that of the Nigerian coke $(0.38 \%)$. Ash contents of $38.53 \%$ for grade $\mathrm{K}$ and $20.56 \%$ for grade $\mathrm{P}$ far exceeded that of both the Chinese $(\leq 11 \%)$ and Nigerian (13.45\%) cokes. Ash content of grade P was comparable to the Indian coke (20.0\%) and Nigerian coal (20.66\%). Nevertheless, volatile matter determined for grade K (20.25\%) and grade $\mathrm{P}(16.25 \%)$ far exceeded that of the Indian coke $(2.0 \%)$ but lower than that in the Nigerian coke $(27.29 \%)$. Volatile matter was also higher compared to the Chinese foundry $(\leq 1.5 \%)$ and Nigerian (2.34\%) cokes. Fixed carbon in grade K was calculated to be $40.60 \%$ and $63.19 \%$ for 
grade P samples. These values were far below the comparable coke types from India (78.0\%), China ( $\geq 88 \%)$ and Nigeria (84.15\%).

Table 1: Proximate analyses of investigated SPACA samples. Results compared with published data on Indian coke, Chinese coke, Nigerian coke, and Nigerian coals.

\begin{tabular}{|c|c|c|c|c|c|c|c|c|}
\hline \multirow{2}{*}{ SN } & \multirow{2}{*}{$\begin{array}{l}\text { Parameters } \\
(\%)\end{array}$} & \multicolumn{2}{|c|}{ Investigated samples } & \multirow{2}{*}{$\begin{array}{l}\text { Indian } \\
\text { coke }^{20}\end{array}$} & \multicolumn{2}{|c|}{ Chinese coke ${ }^{21}$} & \multirow{2}{*}{$\begin{array}{l}\text { Nigerian } \\
\text { coke }^{1}\end{array}$} & \multirow{2}{*}{$\begin{array}{l}\text { Nigeriar } \\
\text { coal }^{3}\end{array}$} \\
\hline & & Grade K & Grade P & & Foundry & Met. & & \\
\hline 1 & Moisture & 0.63 & 0.01 & - & $\leq 5$ & $\leq 5$ & 0.38 & 2.91 \\
\hline 2 & Ash & 38.53 & 20.56 & 20.0 & $\leq 11$ & $\leq 12.5$ & 13.45 & 20.66 \\
\hline 3 & Volatile matter & 20.25 & 16.25 & 2.0 & $\leq 1.5$ & $\leq 1.9$ & 2.34 & 27.29 \\
\hline 4 & Fixed carbon & 40.60 & 63.19 & 78.0 & $\geq 88$ & - & 84.15 & 46.23 \\
\hline 5 & Sulphur & $\leq 0.01$ & $\leq 0.01$ & 0.7 & $\leq 0.65$ & $\leq 0.65$ & 0.14 & 2.91 \\
\hline 6 & Phosphorus & $\leq 0.01$ & $\leq 0.01$ & 0.3 & - & $\leq 0.035$ & - & - \\
\hline
\end{tabular}

Sources $[1,3,20,21]$

Sulphur content was found to be very low in both grades $(<0.01 \%)$. These values meet the criteria for a good foundry coke (Gupta, 2002). They were lower than that determined for Indian $(0.7 \%)$, Nigerian $(2.91 \%)$ and within limits of Chinese $(\leq 0.65 \%)$ cokes. Phosphorus contents of $<0.01 \%$ were recorded for both grades which were lower than Indian coke $(0.3 \%)$ and within range of Chinese metallurgical coke $(\leq 0.035 \%)$.

The SPACA samples investigated were very different in quality as shown in Table 2. The alkali $\left(\mathrm{Na}_{2} \mathrm{O}\right)$ content was high in both samples but higher in grade $\mathrm{K}(28.61 \%)$ than grade $\mathrm{P}(16.10 \%)$. $\mathrm{K}_{2} \mathrm{O}$ in both samples were low. It is obvious that the high level of $\mathrm{Na}_{2} \mathrm{O}$ in SPACA samples as well as $\mathrm{Al}_{2} \mathrm{O}_{3}$ (14.85\% for grade $\mathrm{K}$ and $7.55 \%$ for grade $\mathrm{P}$ ) came from the aluminium smelting processes which condensed on the carbon anode surfaces or penetrated into the anode matrix. The presence of alkali could influence the surface area, chemical structure and catalytic effect of SPACA as foundry coke. It is generally believed that the presence of high alkali could enhance coke reactivity towards oxidizing gases including $\mathrm{CO}_{2}$ [11]. In general, the alkali contents of the aluminisilicates were found to be higher in grade K compared to grade P. Lost on ignition (LOI) was higher in grade $\mathrm{P}$ sample than in grade $\mathrm{K}$ sample, which is expected since grade $\mathrm{P}$ has a higher carbon content. 
Table 2: Chemical composition of investigated coke samples showing major oxides

\begin{tabular}{lllllllllll}
\hline Element (\%) & $\mathrm{Na}_{2} \mathrm{O}$ & $\mathrm{MgO}$ & $\mathrm{Al}_{2} \mathrm{O}_{3}$ & $\mathrm{SiO}_{2}$ & $\mathrm{SO}_{3}$ & $\mathrm{~K}_{2} \mathrm{O}$ & $\mathrm{CaO}$ & $\mathrm{MnO}$ & $\mathrm{Fe}_{2} \mathrm{O}_{3}$ & $\mathrm{LOI}$ \\
\hline Grade $\mathrm{K}$ & 28.61 & 0.28 & 14.85 & 3.66 & 0.28 & 0.10 & 2.37 & 0.01 & 1.19 & 48.60 \\
Grade P & 16.10 & 0.18 & 7.55 & 0.80 & 2.17 & 0.02 & 0.99 & 0.01 & 0.58 & 72.60 \\
\hline
\end{tabular}

XRD was used to characterize the carbon structure of the two samples investigated. Figure 1 shows XRD patterns of the SPACA samples investigated. The (002) peak has been selected since it is generally accepted as the average stack height of the aromatic planes of carbon crystallite $[12,13]$. The chemical structure of carbon in SPACAs were the same for both grades as indicated by a sharpening of the (002) carbon peaks. Additionally, observed background intensity in the XRD patterns of the SPACAs were minimal. Lower background intensity is often indicative of decreasing amorphous carbon content. The peak values were determined and used in the calculation of the crystallite length ( $\mathrm{Lc}$ ) from equation 3. Bragg's equation [14] was used to determine the $\mathrm{d}_{(002)}$ between the graphene sheets. The compiled data is shown in Table 3.

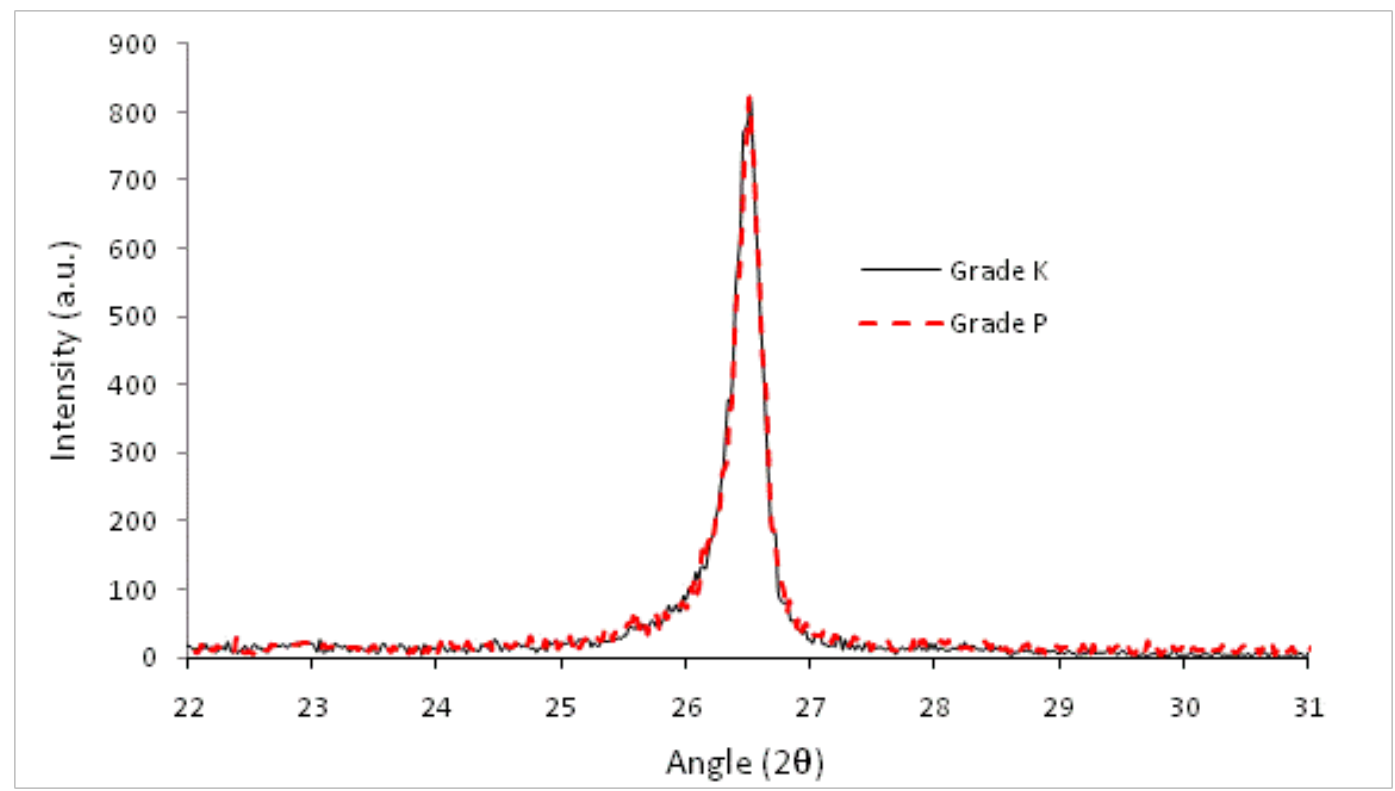

Fig. 1: XRD pattern of SPACA samples investigated (shown from 23 to $302 \theta$ ).

Table 3: Crystallite dimensions of XRD 002 peak. Samples were tested as processed.

\begin{tabular}{lll}
\hline Sample & Grade K & Grade P \\
\hline FWHM $(\theta$ rad $)$ & 0.122 & 0.0965 \\
Peak Position $\left(2 \theta^{\circ}\right)$ & 26.14 & 26.39 \\
Crystallite Length, Lc $(\AA)$ & 4.05 & 5.12 \\
$\mathrm{~d}(002)$ spacing $(\AA)$ & 3.3497 & 3.3751 \\
\hline
\end{tabular}




\section{DISCUSSIONS}

The moisture content of grade K $(0.63 \%)$ was higher than grade P $(0.01 \%)$. During combustion of coke in copula furnace, a greater amount of heat produced is used to evaporate the moisture contained in the coke. Thus, coke grade P will burn faster than coke grade K. Additionally, ash content in grade $\mathrm{P}$ was also lower than in grade $\mathrm{K}$. High ash content lowers the heating value of coke and therefore coke grade $\mathrm{P}$ appears to be of a better coke quality than grade $\mathrm{K}$.

The amount of ash in coke determines the amount of fluxing agents that must be added to the copula charge [15]. As ash content in coke increases, more fluxes are needed which influences slag volume and composition. Without proper fluxing the slag will coat the coke, preventing combustion and bridge in the areas chilled by air from the tuyeres [16]. Increased amount of fluxes lowers the efficiency of the furnace, increases cost of operation and increase waste generation which becomes an environmental concern. Industrial experiences have shown that $1 \mathrm{wt} \%$ increase of ash in the coke reduces metal production by 2 or $3 \mathrm{wt} \%$ [17].

The volatile matters in SPACA grades investigated were very high. A high volatile matter in coke is an indication that the coke has not been properly carbonized. High volatile matter in coke decreases the carbon contents therefore affects heating values. Additionally, high volatile matter causes operational problems in the cleaning of the copula gas [5]. However, comparing the two, grade $\mathrm{P}$ seems to be of better coke quality than grade $\mathrm{K}$. From chemical analysis, grade $\mathrm{P}$ has higher organic matter (LOI of $72.60 \%$ ) than grade $\mathrm{K}$ (LOI of $48.60 \%$ ). This suggests that grade $\mathrm{P}$ would be more reactive to produce more $\mathrm{CO}$ than grade $\mathrm{K}$. It should also be mentioned here that the higher LOI recorded for grade $\mathrm{P}$ is as a result of higher carbon content compared to grade $\mathrm{K}$. Fixed carbon content in grade $\mathrm{K}$ was lower than in grade $\mathrm{P}$ indicating that the latter is of better coke quality than the former. Both samples, however, have lower carbon content compared to the Indian, Chinese and Nigerian cokes been referenced. Low carbon content results in low heating value. The major raw material used in the study area for cupola furnaces is ferrous metal scrap which mainly contains Fe-O compounds. The products from the cupola furnaces are metallic iron which is obtained as a result of the reaction with the coke as shown:

$\mathrm{FeO}_{1.5}+1.5 \mathrm{C}=\mathrm{Fe}+1.5 \mathrm{CO}$

$\mathrm{FeO}_{1.5}+0.75 \mathrm{C}=\mathrm{Fe}+\mathrm{CO}_{2}$

Both reactions are exothermic and are achieved by the controlled combustion of the coke. From the above two equations, reaction (5) requires $50 \%$ less carbon than reaction (4). On the basis of the carbon content in coke grades investigated, reaction (5) rather than (4) would be favoured. This is because the coke grades have less carbon (i.e. less heat) to reduce iron oxide to iron. Though the coke are less expensive (reducing production cost), reaction (5) in turn, corresponds to the emission of $\mathrm{CO}_{2}$. The effects of $\mathrm{CO}_{2}$ on the environment cannot be over emphasised. 
Needless to say, there is a strong incentive to reduce the emission of $\mathrm{CO}_{2}$ from foundry operations. This was one of the areas of interest during the $3^{\text {rd }}$ International Symposium on Sustainable Ironmaking held in Sydney, Australia from 29-30 July, 2010. If these grades of coke are to be used by small scale foundrymen, stringent measures must be put in place to minimize gaseous waste generation. Coke with high carbon content will favour reaction [4] and therefore there would be zero $\mathrm{CO}_{2}$ emission. High cost of foundry coke would also impact on the operations of this industry since production cost will increase.

Sulphur content was found to be lower in grade $\mathrm{K}$ than in grade P. Nevertheless, both grades meet the requirement of quality foundry coke. Sulphur has a great tendency to segregate and can react with iron forming iron sulphide which produces red or hot-shortness since the low melting eutectic forms a network around the grains so that they hold loosely together. Thus, as the sulphur content increases, coke productivity in the copula furnace decreases.

The phosphorus content was also found to be within the specification of a quality foundry coke. High presence of phosphorus has a tendency to react with the iron to form iron phosphide $\left(\mathrm{Fe}_{3} \mathrm{P}\right)$ which has the particularity of being brittle. Hence, phosphorus renders steel less tough and ductile while it increases brittleness.

\subsection{Carbon Structure}

Coke reactivity is influenced by its physical properties, including porosity as well as chemical properties including coke minerals and carbon structure. Powder x-ray diffraction was performed on the two grades of SPACA samples. The crystalline intensity value was determined by integration of the diffraction intensity for the 002 peak of the spent carbon anodes. The crystallite width, Lc, was calculated and found to be $4.05 \AA$ for grade K and $5.12 \AA$ for grade P. It could be observed that Lc values of SPACA grades investigated did not change significantly. Both carbon structures are graphitic in nature because of their hexagonal crystalline structures. The crystallinity of graphitic carbon can be altered through calcinations and graphitization [18]. The crystallite width was smaller compared to published results and had sharper diffraction peaks $[18,19]$. The difference could be attributed to the chemical composition of the coke types investigated which strongly depends on the mineral matter. SPACA samples investigated are more crystalline than regular foundry coke.

\section{CONCLUSION}

The studies conducted have shown that there are two grades of spent prebaked aluminium carbon anodes (SPACAs) from VALCO, an aluminium smelting company in Ghana. SPACA samples have been shown to partially meet the chemical and physical characteristics of a quality foundry coke. Grade P sample has lower moisture, volatile matter and ash content than grade $\mathrm{K}$. 
Additionally, grade $\mathrm{P}$ has higher fixed carbon content than grade $\mathrm{K}$. Both grades have their sulphur and phosphorus contents within requirements of a quality foundry coke. Chemical analysis indicated that grade $\mathrm{P}$ has a higher organic matter than grade $\mathrm{K}$. In general, grade $\mathrm{P}$ is of better foundry coke quality than grade $\mathrm{K}$ and therefore could be used as source of fuel for copula furnaces in small scale foundries in Ghana. However, these grades of coke must be used with caution due to the potential increased in both solid and gaseous waste generation.

\section{REFERENCES}

[1] Adeleke, A.O., Makan, R.S., Ibitoye, S.A., 2006, Characterisation of Ajaokuta coke for blast furnace iron making. J. Min. \& Mat. Charact. \& Eng. 5(2), 155-165.

[2] Adygezalov, S.A. Dvortsov, S.P. Shemonaeva, T.N. Strakhov, V.M. Surovtseva, I.V., 2011, Industrial production of coke briquets for copula smelting of iron. Coke \& Chemistry, 54(1), 19-22.

[3] Akpabio, E.J. Obot, O.W., 2011, Optimization utilization of petroleum coke in Nigerian metallurgical industry. J. Min. \& Mat. Charact. \& Eng., 10(3), 267-278.

[4] Benk, A. Coban, A., 2011, Molasses and air blown coal tar pitch binders for the production of metallurgical quality formed coke from anthracite fines or coke breeze. Fuel Processing Technology, 92, 1078-1086.

[5] Nasirudeen, M.B. Jauro, A., 2011, Quality of Some Nigerian Coals as Blending Stock in Metallurgical Coke Production. J. Min. \& Mat. Charact. \& Eng., 10(1), 101-109.

[6] Sultanguzin, I.A. Isaev, M.V. Kurzanov, S.Y., 2011, Optimizing the production of coke, coal chemicals, and steel on the basis of environmental and energy criteria. Metallurgist, 54(9-10), 600-607.

[7] He, Q. Wang, R. Wang, W. Xu, R. Hu, B., 2011, Effect of particle size distribution of petroleum coke on the properties of petroleum coke-oil slurry. Fuel: In press.

[8] Zhan, X. Jia, J. Zhou, Z. Wang, F., 2011, Influence of blending methods on the cogasification reactivity of petroleum coke and lignite. Energy Conversion and Management, 52, 1810-1814.

[9] Malyutina, E.M. Dyskina, B.S., 2011, Expanding pitch-coke production. Coke \& Chmistry, 54(1), 16-18.

[10] Kubota, M. Ito, T., 2011, Watanabe F, Matsuda H, Pore structure and water adsorptivity of petroleum coke-derived activated carbon for adsorption heat pump-Influence of hydrogen content of coke. Applied Thermal Engineering, 31, 1495- 1498.

[11] Shenqi, X. Zhijie, Z. Jie, X. Guangsuo, Y. Fuchen, W., 2011, Effects of alkaline metal on coal gasification at pyrolysis and gasification phases. Fuel, 90, 1723-1730.

[12] Lu, L. Sahajwalla, V. Kong, C. Harris, D., 2001, Quantitative X-ray diffraction analysis and its application to various coals. Carbon, 39, 1821-1833.

[13] Sonibare, O.O. Haeger, T. Foley, S.F., 2010, Structural characterization of Nigerian coals by X-ray diffraction, Raman and FTIR spectroscopy. Energy, 35, 5347-5353. 
[14] Askeland, D. Phule, P.P., 2006, The science and engineering of materials, International student edition, Canada, Thomson.

[15] Sakurovs, R. Burke, L., 2011, Influence of gas composition on the reactivity of coke. Fuel Processing Technology, 92, 1220-1224.

[16] Haley, D.G., 2004, The efficiency of coke producing quality iron from lower quality coke, www.asi-alloys.com/pdf/GeoHaleyCokePaper.pdf

[17] Diez, M.A. Alvarez, R. Barriocanal, C., 2002, Coal for metallurgical coke production: Prediction of coke quality and future requirements for coke making. Int. J. Coal Geol, 50, 289-412.

[18] Hilding, T., 2005, Evolution of coke properties while decending through a blast furnace. Licentiate Thesis, Luleå University of Technology, Sweden.

[19] Maybury, J.J., 2007, Investigation of the stress induced properties of coke during carbonization. MSc Thesis, West Virginia University.

[20] Gupta, R.B., 2002, Foundry engineering. $3^{\text {rd }}$ ed. New Delhi, Satya Prakashan.

[21] www.hiwtc.com/products. 